\title{
Thermal Decomposition of Printed Circuit Board in the Presence of Zinc Oxide under Inert and Oxidative Atmosphere: Emission Behavior of Inorganic Brominated Compounds
}

\author{
Osamu Terakado ${ }^{*}$, Shunsuke Kuzuhara², Hironori Takagi ${ }^{3}$, Masahiro Hirasawa ${ }^{3}$ \\ ${ }^{1}$ Department of Material and Environmental Engineering, National Institute of Technology, Hakodate College, Hakodate, Japan \\ ${ }^{2}$ Department of Materials and Environmental Engineering, National Institute of Technology, Sendai College, Natori, Japan \\ ${ }^{3}$ Department of Chemical Systems Engineering, Graduate School of Engineering, Nagoya University, Nagoya, Japan \\ Email: ^terakado@hakodate-ct.ac.jp
}

How to cite this paper: Terakado, O., Kuzuhara, S., Takagi, H. and Hirasawa, M. (2018) Thermal Decomposition of Printed Circuit Board in the Presence of Zinc Oxide under Inert and Oxidative Atmosphere: Emission Behavior of Inorganic Brominated Compounds. Engineering, 10, 606-615. https://doi.org/10.4236/eng.2018.109044

Received: August 20, 2018

Accepted: September 18, 2018

Published: September 21, 2018

Copyright (c) 2018 by authors and Scientific Research Publishing Inc. This work is licensed under the Creative Commons Attribution International License (CC BY 4.0).

http://creativecommons.org/licenses/by/4.0/

\begin{abstract}
Thermal degradation of a FR-4 type printed circuit board, PCB, containing brominated flame retardant has been studied both in inert and oxidative atmosphere for the emission control of harmful brominated compounds. The presence of oxygen in atmosphere resulted in the reduction of the yield of hydrogen bromide, one of the major brominated compounds in thermal treatment, and in the enhancement of the formation of bromine and hypobromous acid. The intentional addition of zinc oxide to the PCB powder sample gave rise to the fixation of $\mathrm{Br}$ as zinc bromide. It also resulted in the promotion of the release of brominated compounds in comparison to the case of pure PCB. Thus, the addition of the oxide can be a benefit with respect to the bromine fixation and the kinetics of thermal treatment of PCB as well as metal recovery.
\end{abstract}

\section{Keywords}

Printed Circuit Board, Brominated Flame Retardants, Hydrogen Bromide, Bromine, Emission Control

\section{Introduction}

Waste electrical and electronic equipment, WEEE, contains a variety of valuable metals, such as gold and silver, so that the development of the metal recovery process from WEEE is of great importance for the establishment of sustainable society [1]. Various processes have been proposed so far: conventional ones are 
based on the hydrometallurgical treatments after the combustion of WEEE. It should be noted that many flame retardants are used in electrical and electronic equipment in order to ensure their fire safety. In general, the share of brominated flame retardants, BFRs, reaches up to $40 \%$ [2], so that special attention should be paid in thermal treatment of WEEE, as various brominated compounds, including hydrogen bromide, $\mathrm{HBr}$, and brominated organic compounds, can be emitted during thermal treatment of various types of WEEE containing brominated flame retardants.

In the course of our studies, we have examined the application of metal oxides to the halogen fixation in pyrolysis of polymers containing halogen as monomers and additives [3] [4] [5]. It has been found out that bromine originating from tetrabromobisphenol A, a representative BFR, and a printed circuit board containing BFRs was converted to stable metal halides or oxyhalides; thus the fixation of bromine was realized [4] [5]. Metal oxides are main components of metallurgical wastes which are discharged in huge amount from metallurgical industries. The above results indicate that these wastes can be applied to the bromine fixation reagent. Moreover, there are many metals in PCB. Thus, the influence of the metallic compounds in thermal treatment of $\mathrm{PCB}$ is of great importance, and related studies have been also reported in literature [6] [7] [8] and references therein.

As combustion of WEEE is a main thermal treatment in the metal recovery, it is important to study the influence of oxygen in the atmosphere. In the present work, we studied the influence of the atmosphere and the presence of metal oxides during thermal treatment of a printed circuit board. Zinc oxide, $\mathrm{ZnO}$, was mainly focused as the added oxide, since it showed the great bromine fixation ability [5]. The mass balance of bromine was examined at different experimental time in addition to the formation profile of $\mathrm{HBr}$. These results will be good basis for designing of thermal process of WEEE.

\section{Experimental}

Printed circuit boards, kindly supplied from Hitachi Kasei Co., Ltd. were FR-4 type samples which consisted of epoxy resin and woven glass fibers. The bromine content was 7.2 mass\%, which was determined by a way similar to JIS $\mathrm{K}$ 7392 method [9]. The copper plate, coated on the sample, was removed by aqueous iron chloride solution. The copper-free PCB was crushed by a drill and, then, ground down to the size of less than $250 \mu \mathrm{m}$. The powder was mixed with metal oxide powder as listed in Table $1\left(\mathrm{La}_{2} \mathrm{O}_{3}\right.$ from Kishida Chem. Co., Ltd. and other oxides from Kanto Chem. Co., Ltd.). In the table the added amount is shown, which was determined on the basis of the possible stoichiometric

Table 1. Amount of oxides added to FR-4 sample (in mass\%).

\begin{tabular}{ccccc}
\hline $\mathrm{ZnO}$ & $\mathrm{Fe}_{2} \mathrm{O}_{3}$ & $\mathrm{La}_{2} \mathrm{O}_{3}$ & $\mathrm{CaO}$ & $\mathrm{CuO}$ \\
\hline 2.63 & 2.58 & 9.75 & 1.83 & 2.57 \\
\hline
\end{tabular}


reaction of bromine and the added oxide, namely $\mathrm{ZnBr}_{2}, \mathrm{FeBr}_{2}, \mathrm{LaOBr}, \mathrm{CaBr}_{2}$, $\mathrm{CuBr}_{2}[5]$.

Themogravimetric analysis, TGA, and differential scanning calorimetry, DSC, were carried out with TGA-2050 equipment (TA Instruments) and DSC6300 apparatus (SII), respectively, at the heating rate of $10^{\circ} \mathrm{C} / \mathrm{min}$ under the environment of helium-oxygen gas mixture. The total gas flow rate was maintained at $100 \mathrm{~mL} / \mathrm{min}$. The partial pressure of oxygen was controlled by changing the ratio of the flow rate of oxygen and helium.

Thermal decomposition experiments were carried out in a quartz tube reactor under helium and air atmosphere. The schematic experimental set-up is shown in Figure 1. The size of the reactor was $700 \mathrm{~mm}$ in length and $26 \mathrm{~mm}$ in i.d. The reaction temperature was $800^{\circ} \mathrm{C}$. Further details are described elsewhere [4]. The hydrogen bromide, $\mathrm{HBr}$, formed during the experiment, was captured in a water trap whose bromide ion concentration was monitored with an ion meter (IM-40S, TOA Electronics). The amount of HBrO, captured in the water trap, was determined by iodometry method [10] after the experimental runs. The bromine, $\mathrm{Br}_{2}$, condensed at the cold part of the quartz reactor was collected with the flow of pure water after the experimental run. As the solubility of $\mathrm{Br}_{2}$ to water is not high enough, it was converted to bromide ion by the irradiation of light into the solution. A preliminary experiment showed that the photochemical conversion completed in 15 minutes in the present experimental set-up. The converted $\mathrm{Br}^{-}$concentration was then determined by the ion meter. The char after thermal treatment was characterized by FT-IR (FT-IR 230, JASCO) analysis. The amount of zinc bromide was determined by ICP spectrometer (SPS7800, SII) for the water collected for bromine determination.

\section{Results and Discussion}

\subsection{Influence of Oxygen in the Gas Phase on Pyrolysis Behavior of Pure PCB}

The result of TGA of pure PCB sample at different oxygen composition is shown in Figure 2. The mass reduction around $310^{\circ} \mathrm{C}-350^{\circ} \mathrm{C}$ is considered as the

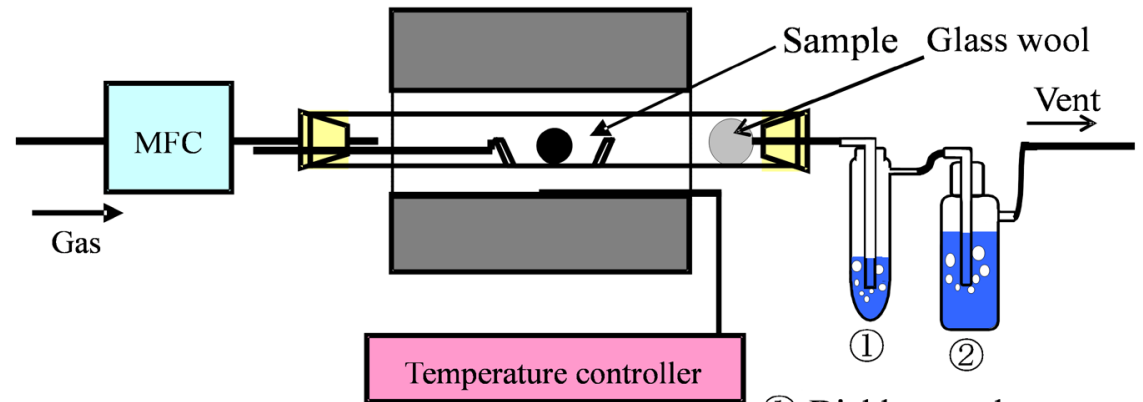

(1) Dichloromethane trap

(2) Water trap

Figure 1. Schematic experimental set-up. Dichloromethane trap was set for the analysis of brominated organic compounds. See Section 3.2. 


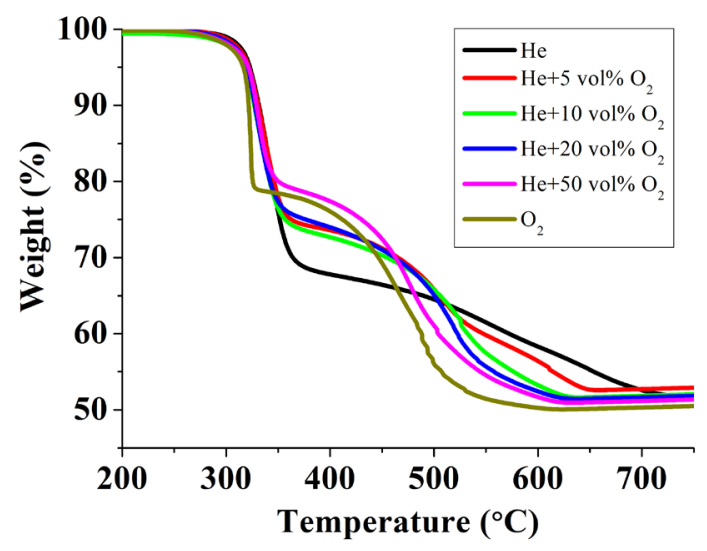

Figure 2. Results of TGA of $\mathrm{PCB}$ at the heating rate of $10^{\circ} \mathrm{C} / \mathrm{min}$ under different atmosphere.

thermal decomposition of epoxy resin, as confirmed by a TGA of synthesized epoxy resins. It is clearly seen that the mass reduction behavior is essentially the same among the different oxygen partial pressures. Thus, the atmosphere does not play an important role in thermal decomposition of epoxy resin. However, the remaining mass after this stage depended on the oxygen composition. It was higher with increasing the composition of oxygen. The results indicate that the oxygen-containing functional group was formed in the char, as observed also in the oxidative decomposition of ABS resin [11].

The formation of oxygen-containing functional group is also confirmed by an FT-IR analysis of the char obtained at $370^{\circ} \mathrm{C}$ under $50 \% \mathrm{O}_{2}$-He atmosphere (Figure 3). The decrease in the transmission, thus the increase in the absorption at $1750 \mathrm{~cm}^{-1}$ was observed for the char obtained under oxidative atmosphere. This IR absorption is assigned to that of the $\mathrm{C}=\mathrm{O}$ stretching mode. Table 2 shows the results of elemental analysis of the char at $370^{\circ} \mathrm{C}$ after the first stage in TG curves. The relative abundance of carbon was higher in case of char obtained under oxidative condition, suggesting that the carbon-oxygen functional groups exist as stable groups in the char.

In contrary to the first mass reduction stage, the second mass reduction stage around $400^{\circ} \mathrm{C}-600^{\circ} \mathrm{C}$ was strongly influenced by the oxygen composition. At elevated oxygen partial pressure, the mass loss finished at lower temperature, indicating the faster kinetics. This stage is, therefore, considered as the oxidation, thus decomposition, of the char matrix which was formed at the first mass reduction stage.

Figure 4 shows the results of DSC at different oxygen partial pressures. Exothermic peaks around $300^{\circ} \mathrm{C}-400^{\circ} \mathrm{C}$ become significant with increasing the composition of oxygen in the gas phase. This is the result of the enhancement of the decomposition of the epoxy resins and possibly the formation of oxygen-containing functional groups. Further studies, such as simultaneous mass spectrometric studies of volatile products, can clarify the physical meaning of these peaks. 


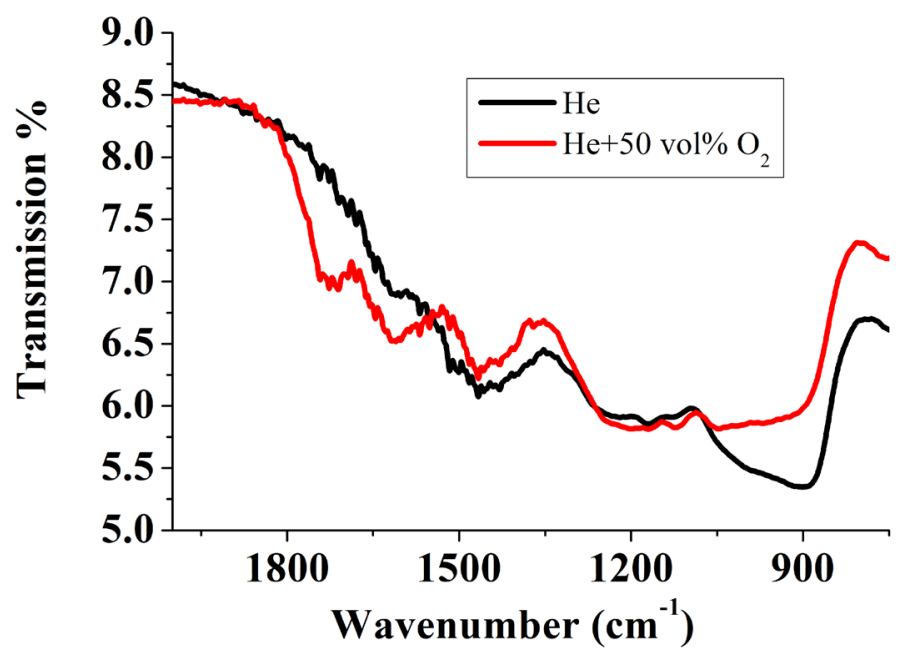

Figure 3. IR analysis of pyrolysis residue at $370^{\circ} \mathrm{C}\left(\right.$ Heating rate $\left.=10^{\circ} \mathrm{C} / \mathrm{min}\right)$.
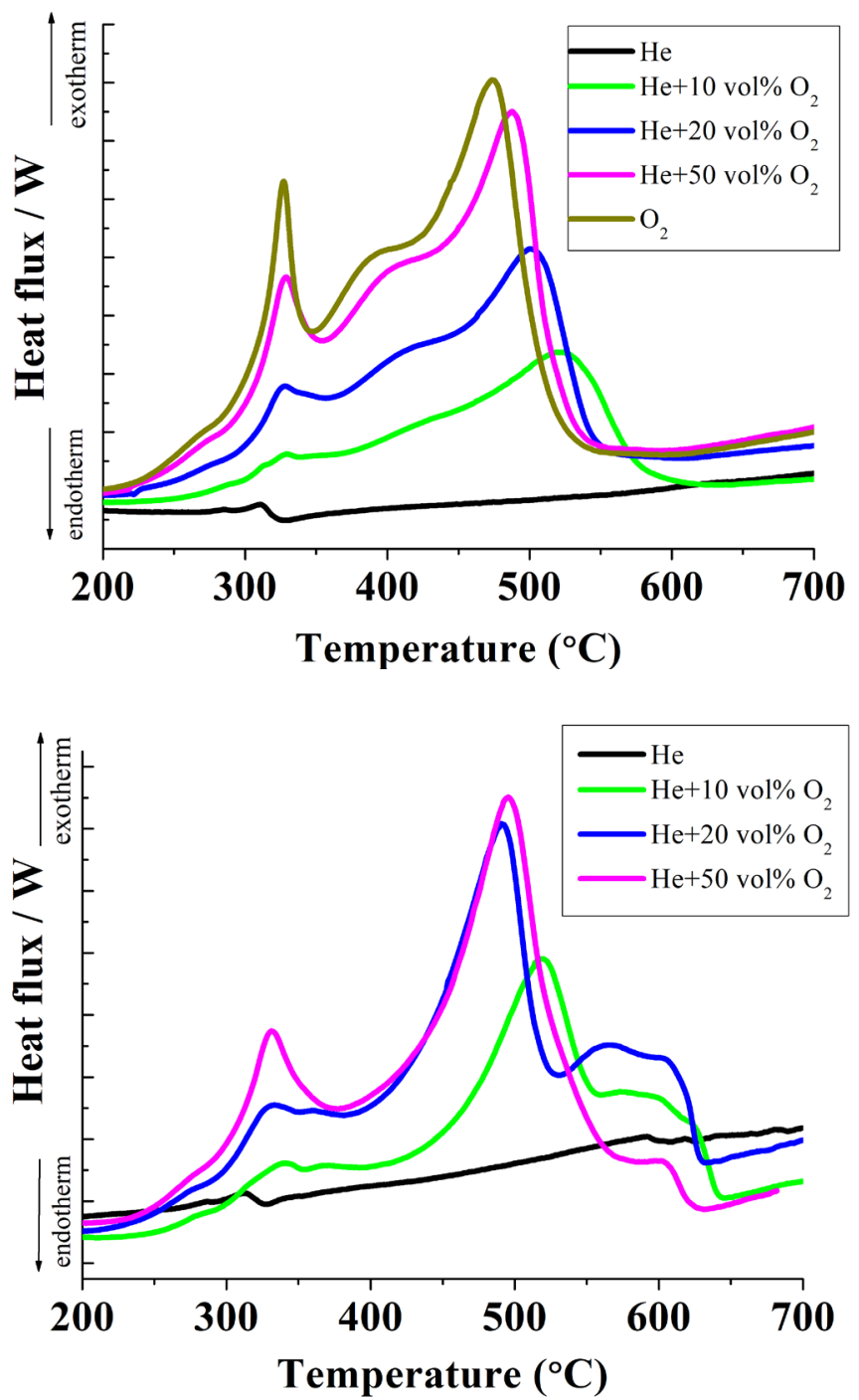

Figure 4. Differential scanning calorimetry analysis of pure PCB (upward) and $\mathrm{PCB}-\mathrm{ZnO}$ mixture (downward) at the heating rate of $10^{\circ} \mathrm{C} / \mathrm{min}$. 
Table 2. Elemental analysis of pyrolysis residue at $370^{\circ} \mathrm{C}$.

\begin{tabular}{cccc}
\hline & $\mathrm{H}$ & $\mathrm{C}$ & $\mathrm{N}$ \\
\hline $\mathrm{He}$ & 1.1 & 14 & 0.33 \\
$\mathrm{He}+50 \mathrm{vol}^{2} \mathrm{O}_{2}$ & 0.76 & 19 & 0.44 \\
\hline
\end{tabular}

Moreover, an exothermic peak around $500^{\circ} \mathrm{C}$ shifts to the lower temperature at elevated oxygen partial pressures, suggesting the enhancement of the gasification of char to $\mathrm{CO}$ and $\mathrm{CO}_{2}$. As a consequent, the mass reduction at $400^{\circ} \mathrm{C}$ $600^{\circ} \mathrm{C}$ in TG curves becomes significant with increasing oxygen partial pressure.

As for the PCB-ZnO mixture, a broad endothermic peak was observed at $600^{\circ} \mathrm{C}-700^{\circ} \mathrm{C}$. This can be attributed to the evaporation of zinc bromide or reduction of $\mathrm{ZnO}$ to metallic zinc [12]. This peak depended on the oxygen partial pressure, so that it would owe to the latter reaction, i.e. redox reaction of zinc-zinc oxide. On the other hand, it cannot explain straightforwardly the peak shift to lower temperature with increasing oxygen partial pressure, as the reduction of $\mathrm{ZnO}$ is not favorable at elevated oxygen partial pressure. Further studies are needed to clarify the reaction mechanism between PCB and $\mathrm{ZnO}$.

\subsection{Emission of $\mathrm{HBr}$ and Brominated Organic Compounds under Inert and Oxidative Atmosphere}

As reported in literature [13] [14], pyrolysis treatment of BFRs and PCB containing them gives rise to the formation of $\mathrm{HBr}$ with by-products of various brominated organic compounds. The formation of $\mathrm{HBr}$ during thermal treatment of PCB was compared both in inert and oxidative atmosphere. Figure 5 shows the bromide ion, $\mathrm{Br}^{-}$, contents in water trap measured by ion meter during thermal treatment of $\mathrm{PCB}$ and $\mathrm{PCB}$-metal oxide mixture. It is clearly seen that much more $\mathrm{Br}^{-}$was observed under inert atmosphere, indicating that almost all bromine in PCB was converted to $\mathrm{HBr}$.

The presence of oxygen in the gas phase resulted in the drastic drop in the yield of $\mathrm{HBr}$. Approximately 40 percent of bromine was converted to $\mathrm{HBr}$ under the oxidative atmosphere of pure PCB. As known in literature [14], the formation of $\mathrm{Br}_{2}$ is dominant in combustion condition.

The addition of metal oxide reduced the formation of $\mathrm{HBr}$ as a result of the formation of metal bromide or oxybromide [5]. Particularly, zinc oxide and lanthanum oxide are effective additives for the suppression of $\mathrm{HBr}$, resulting from the formation of stable $\mathrm{ZnBr}_{2}$ and $\mathrm{LaOBr}$, respectively. The utilization of electric arc furnace dust, huge amount of which is discharged from steel industry, is promising, because it contains many zinc oxide [3] [6] [7].

Another important category of the emission product is the brominated organic compound, BOC. It was found that the $10^{-3}-10^{-4}$ percent of bromine was converted to BOCs in inert atmosphere [5]. However, no BOCs were detected by gas chromatography with mass spectrtometer analysis for the decomposition products under air atmosphere, suggesting that the oxidation of BOCs took place. 

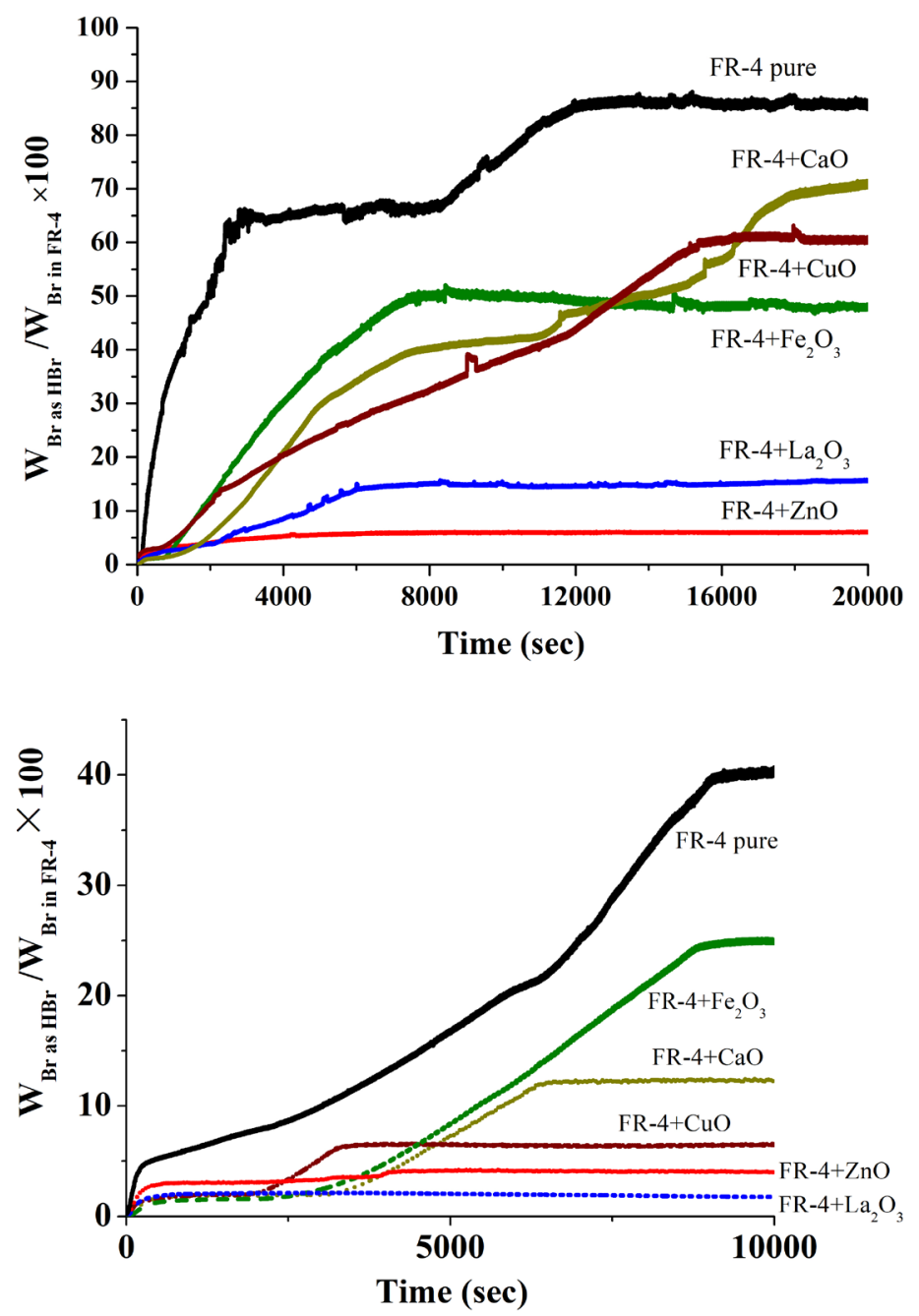

Figure 5. Comparison of the quantitative profile of bromide ion in water trap during heating treatment under helium [5] (upward) and air atmosphere (downward).

\subsection{Emission Profile of Major Inorganic Brominated Products: Comparison between PCB and PCB-ZnO Mixture}

As discussed in the previous section, the intentional addition of $\mathrm{ZnO}$ is attractive, because the formation of $\mathrm{HBr}$ is significantly suppressed. Thus, we studied the influence of $\mathrm{ZnO}$ in detail and examined the bromine mass balance. The yield of $\mathrm{HBr}, \mathrm{Br}_{2}$ and $\mathrm{HBrO}$ evolved at different reaction time is summarized in Figure 6 and Figure 7 for thermal treatment of pure PCB and PCB-ZnO mixture under helium and air atmosphere, respectively.

The gradual increase in the yield of $\mathrm{HBr}$ with time for pure $\mathrm{PCB}$ under helium is the result of the previous section. It is noteworthy that bromine is also formed during the thermal treatment under inert atmosphere, which can be formed by the secondary reaction inside the reactor.

In the case of pure PCB under oxidative atmosphere, the yield of $\mathrm{HBr}$ was considerably low, while that of $\mathrm{Br}_{2}$ and $\mathrm{HOBr}$ is higher in comparison to the case of the inert atmosphere. Obviously, the oxidation of $\mathrm{Br}^{-}$is favorable under the 

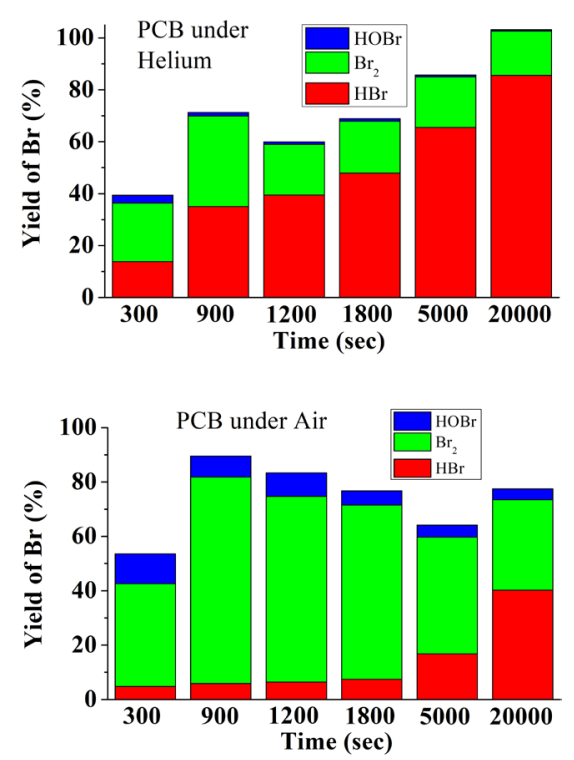

Figure 6. Yield of major brominated compounds for thermal treatment of pure PCB at different reaction time under helium (upward) and air atmosphere (downward). The reaction temperature was $800^{\circ} \mathrm{C}$.
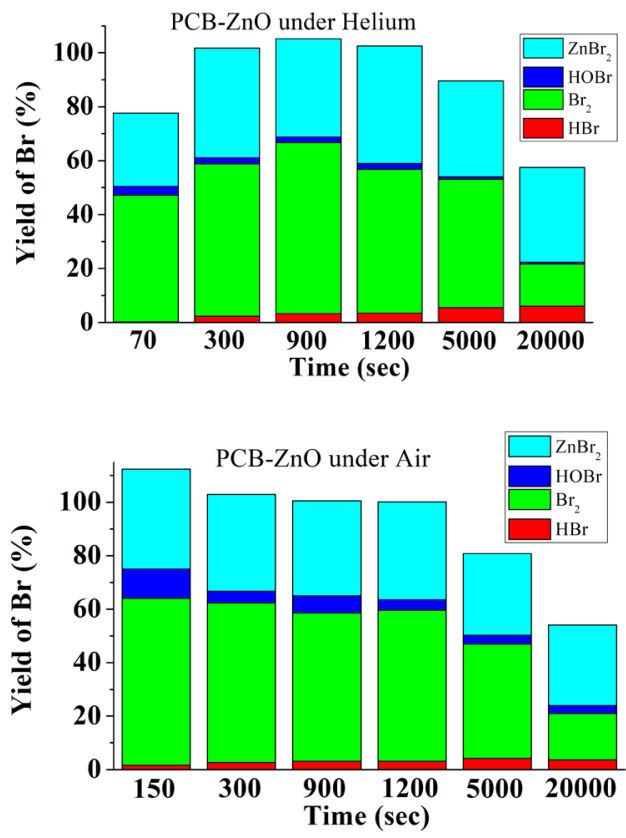

Figure 7. Yield of major brominated compounds for thermal treatment of PCB-ZnO mixture at different reaction time under (upward) helium and (downward) air atmosphere. The reaction temperature was $800^{\circ} \mathrm{C}$.

air atmosphere, leading to the increase in the oxidation state of $\mathrm{Br}$. The apparent decrease in the yield of $\mathrm{Br}_{2}$ with increasing reaction time may arise from the evaporation of volatile bromine from the reactor during thermal treatment of the sample, though relatively large experimental error hinders further discussion.

The addition of zinc oxide led to the fixation of bromine as zinc bromide. A 
satisfactory mass balance was observed at short reaction period, such as 150 seconds within which the release of brominated compounds completed. In contrary, the bromine remained in the solid residue for the sample without oxide in the short reaction time, as the yield of is much lower. The results suggest that the addition of the oxide promotes the decomposition of PCB. The mechanism is still not clear yet, although the formation of zinc bromide and the consequent evaporation can play important roles. The bromide formation is exothermic, so that the local heating of the sample can enhance further decomposition of PCB. The abstract of bromine leads to the decomposition of backbone resins. The consequent evaporation of the bromide causes the flow of the sample, which can agitate the mixing of the sample. Further mechanistic studies of the products can clarify the decomposition of mechanism by the addition of the oxide. It should be here also mentioned that high portion of bromine exists in the reactor for the whole reaction time. Thus, attention should be paid in thermal treatment waste PCBs, and reactor design should be carefully considered.

\section{Summary}

In the present work, thermal decomposition of PCB was studied with emphasis on the emission behavior of brominated compounds under inert and oxidative atmosphere. Bromine mass balance was examined, and it was found that various kinds of brominated compounds were formed during thermal treatment of PCB. The presence of oxygen in the atmosphere resulted in the oxidation of hydrogen bromide to form $\mathrm{Br}_{2}$ and $\mathrm{HBrO}$. The bromine remained in the cold part of the reactor, and then evaporated gradually with time. The intentional addition of oxide, such as $\mathrm{ZnO}$, led to the fixation of bromine as stable zinc bromide, and the release of major inorganic brominated compounds was apparently promoted from PCB. The formation and the evaporation of zinc bromide can owe to the promotion of the decomposition of PCB. Further mechanistic studies, including the examination of the addition of other oxides, are needed to clarify the mechanism.

\section{Acknowledgements}

Financial supports by JSPS KAKENHI Grant Number JP16K00664 are gratefully acknowledged.

\section{Conflicts of Interest}

The authors declare no conflicts of interest regarding the publication of this paper.

\section{References}

[1] Yumoto, T. and Shiratori, T. (2009) Study on Recycling of Metals in WEEE-Investigation of Making an Inventory of Metal Contents. Journal of MMIJ, 125, 75-80. (In Japanese) https://doi.org/10.2473/journalofmmij.125.75

[2] Flame Retardant Chemicals Association of Japan (2018). http://www.frcj.jp/ 
[3] Masuda, Y., Uda, T., Terakado, O. and Hirasawa, M. (2006) Pyrolysis Study of Poly(Vinyl Chloride)-Metal Oxide Mixtures: Quantitative Product Analysis and the Chlorine Fixing Ability of Metal Oxides. Journal of Analytical and Applied Pyrolysis, 77, 159-168. https://doi.org/10.1016/j.jaap.2006.03.001

[4] Terakado, O., Ohhashi, R. and Hirasawa, M. (2011) Thermal Degradation Study of Tetrabromobisphenol A under the Presence Metal Oxide: Comparison of Bromine Fixation Ability. Journal of Analytical and Applied Pyrolysis, 91, 303-309.

https://doi.org/10.1016/j.jaap.2011.03.006

[5] Terakado, O., Ohhashi, R. and Hirasawa, M. (2013) Bromine Fixation by Metal Oxide in Pyrolysis of Printed Circuit Board Containing Brominated Flame Retardant. Journal of Analytical and Applied Pyrolysis, 103, 216-221.

https://doi.org/10.1016/j.jaap.2012.10.022

[6] Grabda, M., Oleszek-Kudlak, S., Shibata, E. and Nakamura, T. (2011) Vaporisation of Zinc during Thermal Treatment of $\mathrm{ZnO}$ with Tetrabromobisphenol A (TBBPA). Journal of Hazardous Materials, 187, 473-479. https://doi.org/10.1016/j.jhazmat.2011.01.060

[7] Grabda, M., Oleszek, S., Shibata, E. and Nakamura, T. (2014) Study on Simultaneous Recycling of EAF Dust and Plastic Waste Containing TBBPA. Journal of Hazardous Materials, 278, 25-33. https://doi.org/10.1016/j.jhazmat.2014.05.084

[8] Kuzuhara, S. and Sano, A. (2018) Bromination of Pd Compounds during Thermal Decomposition of Tetrabromobisphenol A. Engineering, 10, 187-201. https://doi.org/10.4236/eng.2018.104013

[9] Japanese Industrial Standards, JIS K 7392 (2009) Waste Plastics-Test Method for Total Bromine Contents.

[10] Haag, W.R. (1981) On the Disappearance of Chlorine in Sea-Water. Water Research, 15, 937-940. https://doi.org/10.1016/0043-1354(81)90151-2

[11] Camino, G., Costa, L. and Luda di Cortemiglia, M.P. (1991) Overview of Fire Retardant Mechanisms. Polymer Degradation and Stability, 33, 131-154. https://doi.org/10.1016/0141-3910(91)90014-I

[12] Oleszek, S., Grabda, M., Shibata, E. and Nakamura, T. (2012) TG and TG-MS Methods for Studies of the Reaction between Metal Oxide and Brominated Flame Retardant in Various Atmospheres. Thermochimica Acta, 527, 13-21. https://doi.org/10.1016/j.tca.2011.09.014

[13] Marsanich, K., Zanelli, S., Barontini, F. and Cozzani, V. (2004) Evaporation and Thermal Degradation of Tetrabromobisphenol A above the Melting Point. Thermochimica Acta, 421, 95-103. https://doi.org/10.1016/j.tca.2004.03.013

[14] Jin, Y.-Q., Tao, L., Chi, Y. and Yan, J.-H. (2011) Conversion of Bromine during Thermal Decomposition of Printed Circuit Boards at High Temperature. Journal of Hazardous Materials, 186, 707-712. https://doi.org/10.1016/j.jhazmat.2010.11.050 